\title{
Analysis of placental pathology and fetal outcome
}

\author{
Amrutha Ramachandran ${ }^{1,2 *}$ \\ ${ }^{1}$ Department of Obstetrics and Gynecology, Government Stanley Medical College, Chennai, Tamil Nadu, India \\ ${ }^{2}$ Department of Obstetrics and Gynecology, Government Medical College Kozhikode, Kozhikode, Kerala, India
}

Received: 04 February 2018

Accepted: 03 March 2018

\section{*Correspondence:}

Dr. Amrutha Ramachandran,

E-mail: amrutharamachandran@yahoo.com

Copyright: (C) the author(s), publisher and licensee Medip Academy. This is an open-access article distributed under the terms of the Creative Commons Attribution Non-Commercial License, which permits unrestricted non-commercial use, distribution, and reproduction in any medium, provided the original work is properly cited.

\begin{abstract}
Background: A careful examination of placenta along with microscopic study may frequently point to the cause of perinatal death. The American College of Pathologists has provided guidelines for the examination of placenta. Aim of this study was to illustrate the gross and histopathological changes in placenta in certain normal and abnormal pregnancies and to analyse the relationship of placental pathology with fetal outcome.

Methods: A prospective study of 120 deliveries at a tertiary teaching centre in India. Each placenta was studied macroscopically and sent to the pathology department for histological examination. The study included placentas of normal pregnancies and those with maternal high-risk features. The placenta was fixed in formalin and 6 sections were taken. The paraffin sections were studied for vessel wall thickening, infarction, villitis, chorioangiosis, calcification and intervillous hemorrhage. The primary outcome variables were fetal and neonatal morbidity. Abnormal fetal /neonatal events in each histological group were compared with the normal group using $\Psi 2$ test for homogeneity. For cell frequencies less than 5, Fischer exact test was used.

Results: Vessel wall thickening was demonstrated in 54/120 patients (45\%). 7 out of 54 (12.96\%) fetuses were still born in this group compared to $2 / 30(6.67 \%)$ with normal histology ( $p$ value $<0.05$ ). Infarcts were demonstrated in $15 / 120(12.5 \%)$. The occurrence of abnormal neonatal events in this group was significant $\mathrm{p}<0.01$.

Conclusions: Placental histological features of vessel wall thickening, and infarction is associated with abnormal fetal and neonatal outcome. Larger studies are required to establish the inference.
\end{abstract}

Keywords: Fetal outcome, Histological features, Neonatal outcome, Placental pathology

\section{INTRODUCTION}

All communication between a pregnant mother and her fetus is established solely through the placenta and membranes. The placenta is a fascinating organ especially when its functions are considered. During its brief intrauterine existence, the fetus is dependent on the placenta as its lungs liver and kidneys.

Apart from this, the production of steroid hormones and other proteins by human placenta is greater in amount and diversity than that of any endocrine tissue known in all mammalian physiology. Despite its unassailable role in human fetal development, the study of placenta has lagged behind that of fetus. It has not been until recently that clinicians have appreciated the plethora of knowledge that can be gained from the study of placenta.

Difficulties in real time assessment in pregnancy due to largely inaccessible position of the placenta have hampered studies and it is thus called the 'least understood' human organ. A careful examination of placenta along with microscopic study may frequently shed light on many a cause of perinatal death.

The American College of Pathologists and ACOG has provided guidelines for the examination of placenta. ${ }^{1}$ Nowadays when medicolegal problems threaten the 
practicing obstetrician, a study of placenta with histology can prove the exact pathology behind perinatal death and is a legal shield to the doctor from the consumer forum.

The objectives of the present study were to observe the gross and histopathological changes in placenta in certain normal and abnormal pregnancies and to analyse the relationship between placental pathology and fetal outcome.

\section{METHODS}

120 consecutive deliveries at Government RSRM Lying in hospital, Stanley Medical college Chennai was studied over 6 months. Each placenta was studied macroscopically and sent to the pathology department for histological examination.

The study included placentas of normal pregnancies and those with obstetric or neonatal concern for the status of the baby such as preterm, preeclampsia, diabetes, jaundice in the mother, $\mathrm{Rh}$ negative mothers, postdated pregnancies, intra uterine death, abruptio placentae and congenital anomalies in the baby. For each patient, a detailed obstetric history and medical history was taken, clinical examination and routine relevant investigations were done.

All patients were studied with regard to mode of delivery, duration of rupture of membranes, colour of liquor, postpartum complications. Each baby was examined for sex, birth weight, date of birth, apgar at 1 minute and followed up for a period of 1 week. The pregnancies were followed in the post-partum period for prematurity, anomalies, IUGR, IUD, apgar at 1 minute, sepsis, jaundice and death within one week of birth.

\section{Collection of placenta}

Each placenta with $5 \mathrm{~cm}$ cord attached to it was weighed in grams. Placenta was examined macroscopically.

\section{Macroscopic examination}

5 instruments were used for this purpose. A measuring tape, sharp knife, sharp scissors, toothed forceps and calibrated metal cord were used to measure thickness. Each placenta was examined, and the diameter, circumference and thickness were measured.

The examination of placenta includes examination of the maternal surface, amniotic surface, Cut surface, membranes and the umbilical Cord. Maternal surface was examined for the presence or absence of infarction, calcification, fibrin deposits and retroplacental clots. amniotic surface was examined for the colour, cysts, amnion nodosum, calcification, bands, and fibrin deposits. Membranes were examined for the colour, opacity, fetal vessels and membrane insertion. The
Umbilical Cord was examined for the Site of insertion, Length and diameter, vessels and Abnormalities.

\section{Histological examination of placenta}

The placentae were sent to the pathology department after fixing in $10 \%$ formalin. Each placenta was sliced into segments of 1-inch thickness. 6 sections were taken from each placenta, one from membranes and cord, 1 from lateral placental tissue, 2 from superficial placenta, 2 from basal placenta. Paraffin sections were taken and stained with hematoxylin and eosin and pathology reports were prepared. The features studied were vessel wall thickening, infarction, villitis, chorioangiosis, calcification and intervillous hemorrhage. The primary outcome variables were fetal and neonatal morbidity. Abnormal fetal/neonatal events in each histological group were compared with the normal group using $\Psi 2$ test for homogeneity. For cell frequencies less than 5, fischer exact test was used.

\section{RESULTS}

120 consecutive deliveries at RSRM lying in hospital were studied over 6 months. These included both low risk and high-risk pregnancies. Out of these 64 were primigravida and 56 were multigravida. Some patients had more than 1 risk factor. The risk factors are described in Table 1. Out of 120 placentae, $89(74.16 \%)$ placentae were of discoid shape, $21(17.5 \%)$ were ovoid, 7 (5.83\%) were bilobed.

Table 1: Distribution of cases.

\begin{tabular}{|lll|}
\hline Risk factors if any & $\begin{array}{l}\text { No. of } \\
\text { primigravida }\end{array}$ & $\begin{array}{l}\text { No. of } \\
\text { multigravida }\end{array}$ \\
\hline Preeclampsia & 15 & 3 \\
\hline Abruptioplacenta & 1 & 2 \\
\hline PROM & 6 & 4 \\
\hline IUD & 1 & 10 \\
\hline Liver Disease & 2 & 1 \\
\hline Post term & 5 & 2 \\
\hline Heart Disease & 1 & - \\
\hline Preterm & 8 & 7 \\
\hline Anemia & 2 & 3 \\
\hline Rh Negative & 1 & 3 \\
\hline TB complicating & - & 1 \\
\hline Diabetes & - & 1 \\
\hline Congenital Anomalies & 2 & 2 \\
\hline BOH & - & 4 \\
\hline Low risk & 32 & 30 \\
\hline
\end{tabular}

There were 2 cases each of succenturiate placenta and battledore placenta. There was one patient with a membranous placenta. The outcome was poor in succenturiate placenta, both were preterm. The number of cotyledons varies from 10-38 and are incompletely separated by placental septa. The study group showed an average of 20 cotyledons per placenta. The maximum number being 23 and the minimum being 13 . The average number of cotyledons in twins was 30 and did not have 
any functional significance. In majority of the cases the cord insertion was central in $91(75.83 \%)$, followed by eccentric insertion in $28(23.33 \%)$. One case had velamentous insertion. It was an abnormal fetus with anencephaly. The average weight of the placenta in primigravida was 398.75 grams and that in multigravida was 447.72 grams. It is seen that placental weight increases with parity.

Table 2: Fetal growth and placental weight.

\begin{tabular}{|ccccc|}
\hline Fetal Growth & No & $\begin{array}{c}\text { Mean } \\
\text { Placental } \\
\text { weight (in } \\
\text { gms) }\end{array}$ & $\begin{array}{c}\text { Mean } \\
\text { fetal } \\
\text { weight } \\
\text { (in kgs) }\end{array}$ & $\begin{array}{c}\text { Mean } \\
\text { F:P } \\
\text { ratio }\end{array}$ \\
\hline Full term & 78 & 425.52 & 2.9 & 6.83 \\
\hline Preterm(AGA) & 8 & 318 & 2.08 & 6.54 \\
\hline Post term & 8 & 416.25 & 2.76 & 6.63 \\
\hline IUGR & 11 & 375.9 & 2.29 & 6.09 \\
\hline Preterm (SGA) & 6 & 315.8 & 1.86 & 5.89 \\
\hline
\end{tabular}

The mean Feto-placental ratio was 6.83 for full term babies. It was reduced in IUGR, SGA and preterm babies as shown in Table 2. The Mean Feto-placental ratio was reduced in conditions causing chronic uteroplacental insufficiency, such as preeclampsia, and liver disease as described in Table 3.

In a case of gestational diabetes, the ratio was higher (6.67). Analysis of 4 congenitally malformed fetus showed that fetoplacental ratio was reduced in them.
There were $4 \mathrm{Rh}$ negative pregnancies in the study. Fetoplacental ratio of 2 neonates with hydrops fetalis was less when compared to unimmunised fetus's.

Table 3: Feto-placental ratio in high risk cases.

\begin{tabular}{|llll|}
\hline Risk factors & $\begin{array}{l}\text { Mean } \\
\text { placental } \\
\text { weight }(\mathrm{gm})\end{array}$ & $\begin{array}{l}\text { Mean fetal } \\
\text { weight } \\
(\mathrm{kg})\end{array}$ & $\begin{array}{l}\text { Mean } \\
\text { F:P } \\
\text { ratio }\end{array}$ \\
\hline Preeclampsia & 404.7 & 2.48 & 6.14 \\
\hline $\begin{array}{l}\text { Abruptio } \\
\text { placenta }\end{array}$ & 316.67 & 1.97 & 6.22 \\
\hline PROM & 418 & 2.62 & 6.26 \\
\hline IUD & 280 & 1.64 & 5.85 \\
\hline Liver disease & 215 & 1.25 & 5.8 \\
\hline Heart disease & 300 & 1.6 & 5.3 \\
\hline Anemia & 406 & 2.6 & 6.4 \\
\hline Rh negative & 357 & 2.18 & 6.1 \\
\hline TB complicating & 125 & 0.75 & 6.67 \\
\hline Diabetic & 375 & 2.5 & 6.67 \\
\hline $\begin{array}{l}\text { Congenital } \\
\text { anomalies }\end{array}$ & 340 & 2.02 & 5.94 \\
\hline BOH & 193 & 1.24 & 6.42 \\
\hline
\end{tabular}

The commonest histological change in preterm delivery was vessel wall thickening $(80 \%)$ followed by villitis $(46.67 \%)$ and infarction $(40 \%)$ as shown in Table 4 . In term delivery, vessel wall thickening was found in $48.68 \%$ followed by normal histology in $38.15 \%$ and villitis in $32.89 \%$. In placenta of patients who delivered 1 week beyond dates, $50 \%$ had infarction and $87.5 \%$ showed calcification.

Table 4: Analysis of histological features with gestational age.

\begin{tabular}{|c|c|c|c|c|c|c|c|c|}
\hline \multirow{2}{*}{ Histological feature } & \multicolumn{2}{|c|}{ Preterm N=15 } & \multicolumn{2}{|c|}{ Term N=76 } & \multicolumn{2}{|c|}{ Past date $\mathrm{N}=8$} & \multicolumn{2}{|c|}{ Total $\mathbf{N}=120$} \\
\hline & No & $\%$ & No & $\%$ & No & $\%$ & No & $\%$ \\
\hline Vessel wall thickening & 12 & 80 & 37 & 48.68 & 5 & 62.5 & 54 & 45 \\
\hline Infarction & 6 & 40 & 5 & 6.6 & 4 & 50 & 15 & 12.5 \\
\hline Villitis & 7 & 46.67 & 25 & 32.89 & - & - & 32 & 26.66 \\
\hline Chorioangiosis & 1 & 6.67 & 8 & 10.52 & - & - & 9 & 7.5 \\
\hline Calcification & 1 & 6.67 & 19 & 25 & 7 & 87.5 & 27 & 22.5 \\
\hline Intervillous hemorrhage & 1 & 6.67 & 21 & 27.63 & 12.5 & 23 & 23 & 15.8 \\
\hline Normal & 1 & 6.67 & 29 & 38.15 & - & - & 30 & 24.79 \\
\hline
\end{tabular}

\section{Analysis of histological features with fetal outcome}

Vessel wall thickening was identified in 54 patients (45\%), 6 had Apgar $<5 / 10$ while 2 neonates of normal histology had Apgar <5/10. The occurrence of IUD was significantly high when compared to those with normal histology, $\mathrm{p}<0.05$ as shown in Table 5.

The vessel wall thickening was mild in 30 (55.5\%), moderate in $18(33.3 \%)$ and marked in $6(11.15)$. Vessel wall thickening was identified in normal new born also but it was of a milder type. 15 Placentae (12.5\%) had infarction characterized by ischemic villous necrosis with ghost like villi with diffuse fibrinoid material. Six were preterm births of which 2 had preeclampsia; 3 were IUD, 1 neonate had Apgar $<5$ at 1 minute. Infarcts were seen in normal new born also but to a lesser extent. The incidence of abnormal neonatal events was significant when compared to the normal group, $\mathrm{p}<0.01$ as shown in Table 6. 
An increase in sepsis and preterm labour was found in placenta showing villitis, but it was not statistically significant. Villitis was identified in placentas of normal neonates also but it was more of mild variety.

Table 5: Analysis of placenta with vessel wall thickening.

\begin{tabular}{|c|c|c|c|c|c|}
\hline \multirow{2}{*}{ Neonatal Outcome } & \multicolumn{2}{|c|}{ Vessel wall thickening $N=54$} & \multicolumn{2}{|c|}{ Normal histology $\mathbf{N}=\mathbf{3 0}$} & \multirow{2}{*}{ P value } \\
\hline & No & $\%$ & No & $\%$ & \\
\hline 1 min apgar $<5 / 10$ & 6 & 11.11 & 2 & 6.67 & \multirow{8}{*}{$\begin{array}{l}\text { SD } p<0.05 \\
\Psi^{2} \text { ld.f }= \\
5.69\end{array}$} \\
\hline Infections & 3 & 5.55 & 1 & 3.33 & \\
\hline Anomalies & 2 & 3.92 & - & - & \\
\hline Death in 1 week & 5 & 9.25 & - & - & \\
\hline Preterm birth & 10 & 18.5 & 1 & 3.33 & \\
\hline IUD & 7 & 12.96 & 2 & 6.67 & \\
\hline IUGR & 3 & 3 & 2 & 6.67 & \\
\hline Normal Newborn & 25 & 25 & 22 & 73.33 & \\
\hline
\end{tabular}

Table 6: Analysis of placentas with infarction.

\begin{tabular}{|c|c|c|c|c|c|}
\hline \multirow{2}{*}{ Neonatal outcome } & \multicolumn{2}{|c|}{ Infarction $\mathbf{N}=15$} & \multicolumn{2}{|c|}{ Normal histology $\mathbf{N}=\mathbf{3 0}$} & \multirow{2}{*}{ P value } \\
\hline & No & $\%$ & No & $\%$ & \\
\hline 1 min apgar $<5 / 10$ & 1 & 6.67 & 2 & 6.67 & \multirow{8}{*}{$\begin{array}{l}\mathrm{SD} \\
\mathrm{P}<0.01 \\
\Psi^{2} \text { ld } . \mathrm{f}=8.95\end{array}$} \\
\hline Infections & - & - & 1 & 3.33 & \\
\hline Anomalies & 1 & 6.67 & - & - & \\
\hline Death in 1 week & 1 & 6.67 & - & - & \\
\hline Preterm birth & 6 & 40 & 1 & 3.33 & \\
\hline IUD & 3 & 20 & 2 & 6.67 & \\
\hline IUGR & 4 & 26.67 & 2 & 6.67 & \\
\hline Normal newborn & 4 & 26.67 & 22 & 73.33 & \\
\hline
\end{tabular}

Villitis was mild in 20 patients $(62.5 \%)$, moderate in 5 $(15.62 \%)$, diffuse in $7(21.87 \%)$. A patient with pulmonary tuberculosis was demonstrated to have mild villitis. Section studied also showed epitheloid granuloma. 9 placentas had chorioangiosis characterized by increase in number of capillaries per villi. On comparing with normal group, 1-minute Apgar <5/10 was seen in $22.2 \%$, but it was not statistically significant. Calcification was identified in placentas of post term and term neonates. It was not correlated with abnormal fetal outcome. 23 placentas with intervillous hemorrhage were studied. The incidence of IUD was $17.39 \%$ and IUGR was $17.3 \%$. However, it was not statistically significant. The placentas had features other than those studied in detail. They include fibrin deposits, villous edema and hyaline changes. The neonatal outcome was not statistically significant for these features when compared to the normal group.

\section{DISCUSSION}

\section{Placental size and weight}

According to Benirschke et al the normal placenta at term is on average $185 \mathrm{~mm}$ in diameter and $23 \mathrm{~mm}$ in thickness with average volume $497 \mathrm{ml}$ and weight 508 gms. ${ }^{2,3}$ In our study, the average size was $19 \mathrm{~cm}$ and thickness $2.16 \mathrm{~cm}$. In this series, the average weight of placentas in primigravida was 398.75 gms and that in multigravida was 447.72 gms. The placenta of multigravida weighed more than primigravida.

\section{Placental villous architecture}

Human placenta is described as hemochorio endothelial. ${ }^{4}$ Maternal blood bathes the syncitiotrophoblast and villi and is separated from the fetal blood by endothelium lining the fetal blood vessels.

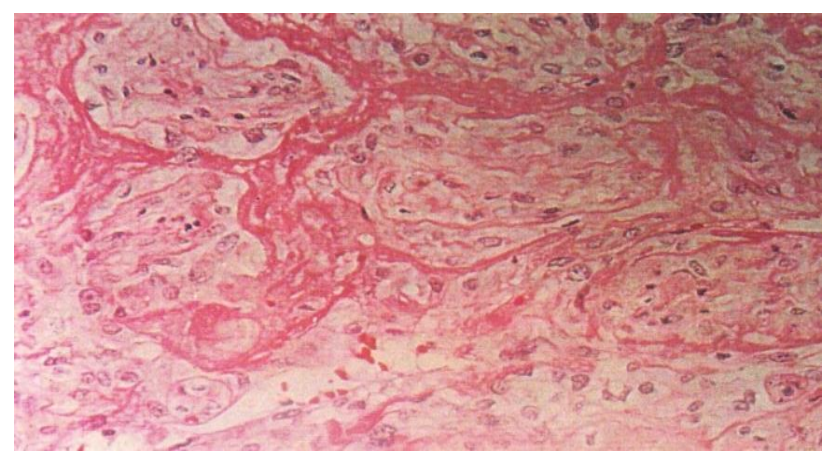

Figure 1: Vessel wall thickening with ischemic changes. 
There are 5 types of placental villi. Mesenchymal villi apppear at 7-8 weeks of pregnancy and the reticular appearance persists till 14 weeks. Apparent spaces are actually stromal channels. Terminal villi appear at 30 weeks. Also, there are, immature intermediate villi, mature intermediate villi and stem villi as shown in Figure 1.

Rohr Fibrinoid is the condensed extracellular material near the intervillous spaces and Nitabuch layer is the deeper layer of fibrinoid tissue. Blood from the maternal decidual spiral artery enters the intervillous space and fills the intra-cotyledonary cavity. The venous openings in the basal plate are arranged about the periphery.

Indications for placental examination were reported by Altshuler et al. ${ }^{1,5}$ They include maternal conditions like diabetes mellitus, preeclampsia, premature rupture of membranes, preterm delivery (before 37 weeks), post term delivery >42 weeks, unexplained fever, poor previous obstetrical history and h/o drug abuse including cocaine.

Fetal and neonatal characteristics requiring placental examination include still birth, neonatal death, multiple gestation, prematurity, intra uterine growth retardation, congenital anomalies, erythroblastosis fetalis, transfer to neonatal ICU, ominous fetal heart tracings, presence of meconium and low apgar scores.

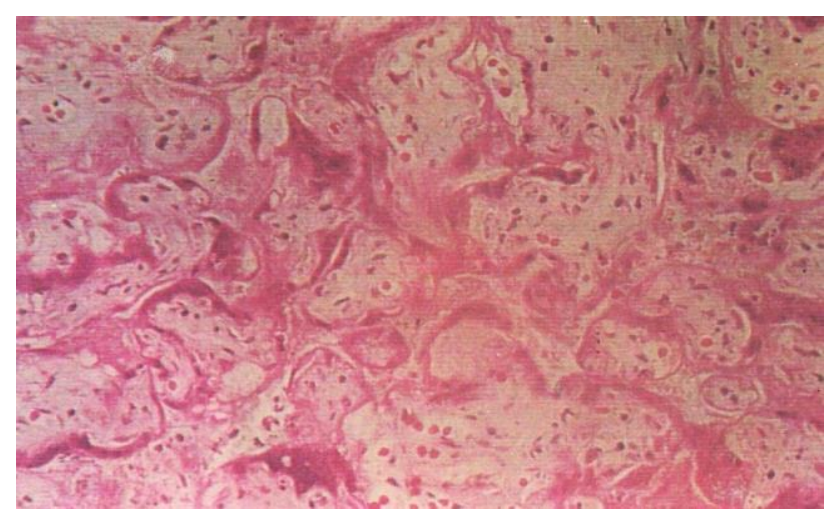

Figure 2: Infarct with ghost like villi.

Kaplan et al has studied the fetoplacental ratio in detail. ${ }^{5}$ The ratio was found to be 4 at 24 weeks and increases to 7 at term. The ratio is reduced in hydrops fetalis and diabetes and the ratio is increased in uteroplacental insufficiency.

The feto placental ratio is more significant of fetal well being than weight of the placenta alone. In this study, the average feto placental ratio is reduced in preeclampsia, IUD, liver disease and BOH (Figure 2).

According to Richard and Naeye et al feto placental ratio is increased in conditions of chronic placental insufficiency and reduced in conditions causing placentomegaly like $\mathrm{Rh}$ incompatibility, syphilis and diabetes. ${ }^{6,7}$

\section{Shape}

Irregular non-ovoid shapes are due to abnormalities of implantation, failed involution of chorion levae and intracavitary uterine abnormalities. ${ }^{8}$ They result in retained placenta, velamentous vessels, placenta previa and premature placental separation. In this series, the shape of the placenta was discoid in $74.16 \%$, ovoid in $17.5 \%$ and bilobed in $5.83 \%$. According to Benirschke et al $81.6 \%$ were round, $16 \%$ ovoid and $2.4 \%$ irregular. ${ }^{2,8}$

In succenturiate placenta accessory lobes are seen in addition to normal placenta. Placenta membranaceae is thin expansive placenta. Circummarginate placenta is a condition where a rim of placental tissue is seen extending beyond the vascular plate with margins having fibrin probably due to abnormal placentation/development. Circumvallate placenta is similar to circummarginate placenta but membrane folds and hemorrhage is seen at the margins causing PROM, prematurity and Antepartum hemorrhage..$^{2,8}$

In a series of 1,95,000 cases studied by Benirschke and Kaufmann, had marginal insertion (7\%) and velamentous insertion in $0.83 \%$. In this series central insertion was found in the majority in $75.2 \%$, eccentric in $23.14 \%$, marginal in $5.3 \%$, velamentous insertion in $0.83 \%$.

The identification of velamentous insertion of cord antenatally is important because it can cause catastrophic fetal blood loss after rupture of membranes producing fetal distress. The incidence of the condition is $1 \%$ and is associated with fetal anomalies and vasa previa. ${ }^{2,8}$

\section{Cord complications}

In this study, long cord was found in $0.83 \%$ and short cord in $0.83 \%$. Edema of the cord was seen in all cases of IUD. A case of twin pregnancy (twin II) with anencephaly showed a single umbilical artery. The incidence of single umbilical artery according to Benirschke and Dodds was $0.85 \%$ in singleton and $5 \%$ of all cords in at least one twin. ${ }^{2}$ The incidence of congenital anomalies in such fetuses is higher $18-68 \%$. They include renal aplasia, neural tube defects, limb reduction defects and atresia of hollow organs.

The incidence of single umbilical artery is $0.5-1 \%$, according to Geipel et al single umbilical artery arises due to primary agenesis or atrophy and are associated with congenital anomalies in $20 \% .{ }^{9}$ It is associated with an increase in perinatal morbidity and mortality.

On analyzing placenta of fetuses with congenital anomalies, it was found that the fetoplacental ratio was reduced in all. 2 were twins of the dichorionicdiamnionic variety. Twin 1 had a large meningocele and the baby 
expired after 1 day. Twin 2 had anencephaly and single umbilical artery. The placenta of twin 2 was membranous type with velamentous cord insertion. It was removed manually as it was retained in the uterus. One fetus had cystic hygroma with multiple other defects like short cord, absent nares, fusion of thorax to the head.

The placenta was enlarged and edematous. Later the condition was diagnosed to be a case of non-immune hydrops. Benirschke et al associates abnormal fetal development to placental development. Malformations and disruption of placenta and body wall are seen inbody stalk anomaly, limb body wall complexes, acardia, TRAP, sirenomelia and other anomalies. ${ }^{2}$

Analysis of placenta of $4 \mathrm{Rh}$ negative mothers in this series showed that fetal outcome was poor in three of them. Two babies had hydropsfetalis showing placentomegaly, edema and pale placenta. The fetoplacental ratio was reduced in both. One baby expired after 2 days due to extreme prematurity.

\section{Histological analysis of placenta}

Placental Samples from 120 consecutive deliveries were sent for histopathological analysis. They included both low risk and high-risk pregnancies. In this series $24.79 \%$ had normal histology, $45 \%$ had vessel wall thickening, $12.5 \%$ had infarction, villitis in $26.66 \%$ chorioangiosis in $7.5 \%$, calcification in $22.5 \%$ and intervillous hemorrhage in $19.16 \%$. The frequency of placental features was analysed in relation to selected newborn characteristics like Apgar at 1 minute, infections, anomalies, death in 1 week, preterm birth, IUD, IUGR. For comparison, normal featured placenta and their outcome was compared. Abnormal fetal /neonatal events in each histological group were compared with the normal group using $\Psi 2$ test for homogeneity. For cell frequencies less than 5, Fischer exact test was used.

The association of abnormal neonatal events with vessel wall thickening was significant $-\mathrm{p}<0.05$. The incidence of neonates with 1 minute Apgar $<5 / 10$ preterm birth and IUD was also significantly high in this group. This supports the hypothesis that adverse neonatal outcome was probably due to ischemia resulting from decreased uteroplacental blood flow. ${ }^{10}$

An unexpected finding was the occurrence of vascular changes in the placenta of healthy newborns. However, these lesions were of mild variety. Figure 1 shows changes seen with vessel wall thickening. Analysis of infarction in placenta revealed that preterm labour, IUD, and death within 1 week was higher in this group. Statistical analysis showed that the incidence of abnormal neonatal events in placentas with infarction was significant $\mathrm{p}<0.01$. Areas of infarct appear as ghost like villi as shown in Figure 2.
Sato et al studied the placental findings and maternal and fetal factors in the cases of IUGR $(n=257$, mean maternal age, 30 years; gestational weeks, 34 weeks) and normal growth pregnancies $(n=258$, mean maternal age, 30 years; gestational weeks, 33 weeks), and determined risk factors for IUGR. Pathologically, the prevalence of infarction (33\% vs. $14 \%, \mathrm{P}<0.05)$, fetal vessel thrombosis $(22 \%$ vs. $6 \%, \mathrm{P}<0.001)$ and chronic villitis $(11 \%$ vs. $3 \%, \mathrm{P}<0.001)$ were higher in IUGR cases than those in normal growth pregnancies. ${ }^{11}$ These findings are similar to this study where vessel wall thickening, infarction and villitis were significantly associated with abnormal neonatal events.

On analyzing the group with villitis, the number of newborns with 1 min Apgar $<5 / 10$ was higher. Most important was the incidence of sepsis in the neonates of this group but it was not statistically significant probably due to the small sample size. Villitis was seen in placenta of normal newborn also, but it was of mild type. Chorioamnionitis with a bacterial cloud is shown in Figure 3.

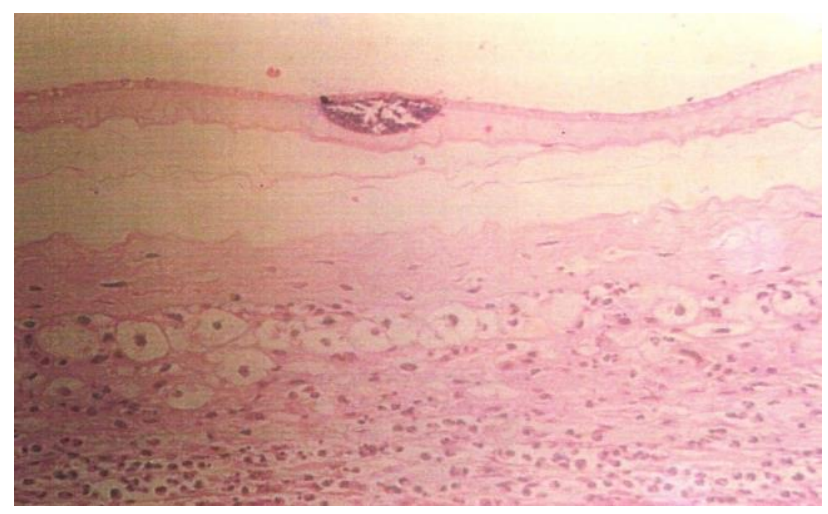

Figure 3: Chorioamnionitis with bacterial cloud.

According to Altshuler and Hyde, chorioamnionitis is involved in the pathogenesis of preterm labour, fetal hypoperfusion and brain damage. ${ }^{1,2,6}$ Katz et al in a study of 128 newborns with prolonged rupture of membranes showed that 64 had evidence of histological chorioamnionitis. Gestational age, birth weight, and Apgar scores were significantly lower in this group. ${ }^{10}$ These findings are similar to our study.

The incidence of neonates with apgar at 1 minute $<5 / 10$ was higher when the histological feature of chorioangiosis was analysed but it was not statistically significant. Chorioangiosis was characterized by excess of fetal vessels in the terminal villi as the try to overcome the diminished maternal blood flow. ${ }^{2}$ The association of calcification with fetal outcome was not significant as a majority of normal healthy newborns also showed this feature. Intervillous hemorrhage is characterized by breaks in the villous epithelium secondary to ischemia and showed a higher incidence of IUD, IUGR and newborn with 1 min Apgar <5, but it was not statistically significant. Figure 4 shows macrophages in the 
intervillous spaces and Figure 5 shows perivillous fibrin deposits.

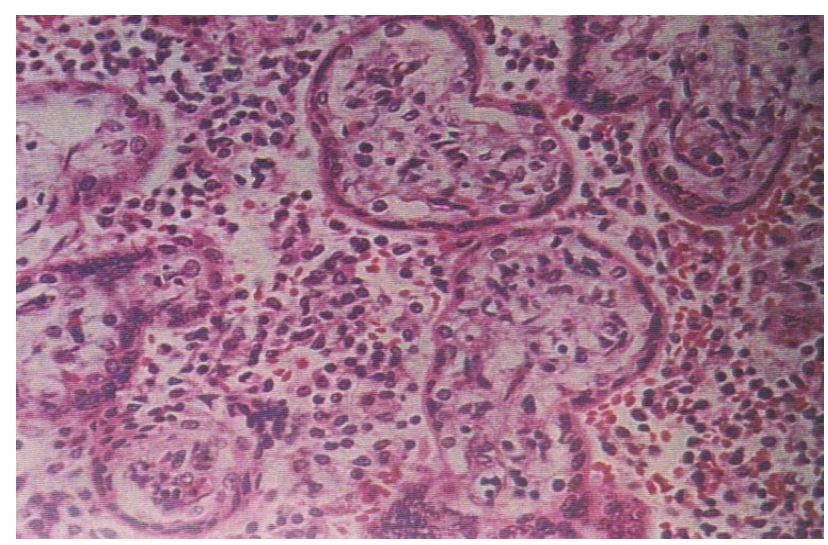

Figure 4: Macrophages in the intervillous spaces.

Marcorelles in a bibliographic review using the Medline and PubMed databases suggests that umbilical cord anomalies, fetal thrombotic vasculopathy, chronic villitis of unknown etiology and chronic histiocytic intervillositis are related to fetal growth restriction. However, there is no direct link between a type of placental pathology and the infant's adverse outcome or his neurological risk. The maternal risk of recurrence is not easily predictable except for the chronic histiocytic intervillositis in which the estimated recurrence rate is very high. In the present study, chronic histiocytic intervillositis was not studied. ${ }^{12}$

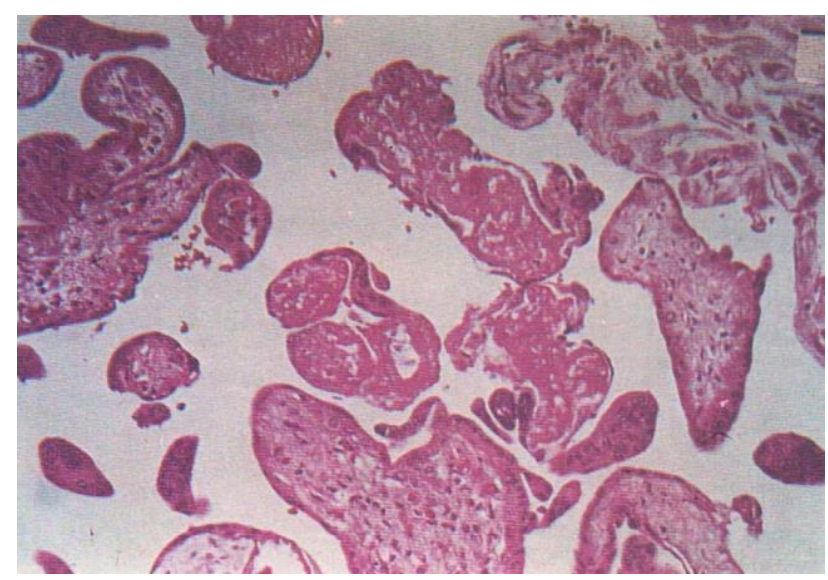

Figure 5: Perivillous fibrin deposits.

One major implication of this study is that gross and histopathological examination of placenta provides insight into neurological illnesses that may occur later in life. It could help protection from medico legal issues to the practicing obstetrician. Existing data and samples can be utilized to identify newer markers and molecular signatures for understanding the biology of normal and adverse pregnancy outcomes.

The Human placenta project launched in the United States and the China Human Placenta project launched in September 2015 shows promising results. Using the banked placentae, the omic studies of spontaneous preterm birth and preterm premature rupture of membranes have expanded from genomics to expression profiling, epigenomic regulation and metabolomic profiling of non-peptide metabolites. ${ }^{13,14,15}$

The strength of the study is that it is a prospective, single institution analysis with a short inclusion period. All pathological examinations were done by a single dedicated pathologist. Therefore, it reduces bias due to changes in the patterns of specimen collection as well as interpretation of pathological slides. A limitation is the nonrandomized design, small sample size and the short follow up of 1 week. Also, proteomic or genomic study on the placental tissue would have identified key gestational stage signatures. ${ }^{16}$

\section{CONCLUSION}

Certain placental histological features like vessel wall thickening and infarctionare associated with abnormal fetal and neonatal events. The feto- placental ratio is altered in IUGR and prematurity. It is also reduced in conditions producing placental insufficiency such as preeclampsia and chronic medical conditions. Placentais a readily accessible specimen that assists in clinical diagnosis and to identify the aetiopathology of diseases of pregnancy and newborn

\section{ACKNOWLEDGMENTS}

The author would like to thank Prof A. Sundaram, Professor and Head of the Department of Pathology, Stanley Medical College Chennai for his personal interest and encouragement at every step of this study. All the slides were read and interpreted by him with great kindness.

The author would also like to thank $\mathrm{Dr} R$ Thirupurasundari, Dr CT Vela, Dr,V Madhini, Dr A Sivathalam, Dr S Saraswathi, Dr Sorna Velayudham, Dr R Premlatha, Dr Hephzibah , DrHemavathy , Dr Krishnaveni and Dr Nageshwari for their support.

Funding: No funding sources

Conflict of interest: None declared

Ethical approval: Obtained from the Institutional review board, Stanley Medical College.

\section{REFERENCES}

1. Altshuler G, Deppisch LM. College of American pathologist's conference XIX on the examination of the placenta. Report of the working group on indications of placental examination. CAP placenta consensus conference. Arch Pathol Lab Med. 1991;115;701-3.

2. Benirschke K, Kaufmann P, Baergen R. Pathology of the Human Placenta. 5th ed. New York, Springer Verlag; 2012. 
3. Fox GE, Van Wesep R, Resau JH, Sun CC. The effect of immersion formaldehyde fixation on human placental weight. Arch Pathol Lab Med. 1991 Jul;115(7):726-8.

4. Novak RF. A brief review of the anatomy, histology, and ultrastructure of the full-term placenta. Arch Pathol Lab Med. 1991 Jul;115(7):654-9.

5. Langston C, Kaplan C, Macpherson T, Manci E. Practice guideline for examination of the placenta. Arch Pathol Lab Med. 1997 May;121(5):449.

6. Naeye R, Travers H. College of American Pathologists conference on the examination of placenta: Report of the working group on the role of the pathologist in malpractice litigation involving placenta. Arch Pathol Lab Med. 1995;115:717-9.

7. Roberts DJ, Post MD. The placenta in pre-eclampsia and intrauterine growth restriction. J Clin Pathol. 2008 Dec;61(12):1254-60.

8. Corton M, Leveno K, Bloom S, Dashe J, Spong C. Williams Obstetrics, 24th Edi. McGraw Hill. 13:9780071798398.

9. Geipel A, Germer U, Welp T, Schwinger E, Gembruch U. Prenatal diagnosis of single umbilical artery: determination of the absent side, associated anomalies, Doppler findings and perinatal outcome. Ultrasound Obstet Gynecol. 2000 Feb 1;15(2):114-7.

10. Tachibana M, Nakayama M, Miyoshi Y. Placental examination: prognosis after delivery of the growthrestricted fetus. Curr Opin Obstet Gynecol. 2016 Apr $1 ; 28(2): 95-100$.
11. Katz N, Schreiber L, Oron A, Halachmi S, Kohelet D. Inflammatory response in preterm newborns born after prolonged premature rupture of membranes: is there a correlation with placental histological findings?. IMAJ. 2017 Oct;19(10):610-3.

12. Sato Y, Benirschke K, Marutsuka K, Yano Y, Hatakeyama K, Iwakiri $\mathrm{T}$ et al. Associations of intrauterine growth restriction with placental pathological factors, maternal factors and fetal factors; clinicopathological findings of 257 Japanese cases. Histol Histopathol. 2013 Jan;28(1):127-32.

13. Marcorelles P. Placental features in intrauterine growth retardation. J Gynecol Obstet Reprod Biol. 2013 Dec;42(8):996-1007.

14. Zhong N, Zhong M. China Human Placenta Project: A global effort to promote placenta medicine. Placenta. 2016 Aug;44:112-3.

15. Guttmacher AE, Maddox YT, Spong CY. The Human Placenta Project: placental structure, development, and function in real time. Placenta. 2014 May;35(5):303-4.

16. Armstrong DL, McGowen MR, Weckle A, Pantham $\mathrm{P}$, Caravas J, Agnew D et al. The core transcriptome of mammalian placentas and the divergence of expression with placental shape. Placenta. 2017 Sep;57:71-8.

Cite this article as: Ramachandran A. Analysis of placental pathology and fetal outcome. Int J Reprod Contracept Obstet Gynecol 2018;7:1322-9. 